\title{
Análise dos serviços ecossistêmicos em reservatórios da Região Nordeste Semiárida do Brasil
}

\author{
Analysis of ecosystem services in the region reservoirs semiarid Northeast Brazil
}

Oliveira $^{1}$, A.M.; Costa $^{2}$, D. F.S.; Araújo ${ }^{3}$, W. S.; Silva ${ }^{4}$, E. E.S.

alissongeoliveira@gmail.com;

\section{Resumo}

Historicamente, os reservatórios hídricos representam uma importante estratégia para a permanência de uma sociedade ou povo, em determinado local. Além disso, estes são responsáveis por prover diversos benefícios à sociedade, conhecidos como serviços ecossistêmicos. Nesse contexto, a construção destes reservatórios trata-se de uma importante política pública para o semiárido brasileiro, sendo peça chave para a permanência da sociedade nessa região. A pesquisa em questão tem o intuito de discutir a importância dos reservatórios artificiais, no tocante aos diversos serviços ecossistêmicos prestados por estes. A identificação destes serviços foi realizada, mostrando a importância destes. Em seguida, foi realizada a identificação destes serviços, visando a importância e valorização destes, e posteriormente utilizou-se o quadro DPSIR, como forma de evidenciar a importância destes reservatórios, possibilitando também uma análise os serviços prestados. Concluiu-se que diversos serviços são oferecidos, como abastecimento de água e apreciação da paisagem. Alguns dos serviços de regulação necessitam de análise mais detalhada, como a polinização, para a agricultura tradicional praticada pelos moradores do semiárido.

Palavras-chave: Serviços ecossistêmicos, barragens, DPSIR.

\begin{abstract}
Historically, water reservoirs represent an important strategy for permanence of a society or people in a particular place. In addition, they are responsible for providing many benefits to society, known as ecosystem services. So, many water reservoirs were constructed as important public policy for the Brazilian semiarid region for permanence of people in this region. This research aims to discuss the importance of artificial reservoirs for providing ecosystem services by human well-being in this region. The identification of these services was carried out, aimed at the importance and value of these, and later used the DPSIR framework as a way of highlight the importance of these reservoirs, allowing also an analysis of the services provided. It was concluded that many tangible and intangible ecosystems services were provided, so water supply to landscape and spiritual appreciation. Many services of regulation need to be better analyzed, as the important service for local and regional weather ammonization, as well as the pollinizator for traditional agriculture of semi-arid residents.
\end{abstract}

Keywords: Ecosystems services, dam's, DPSIR.

\section{INTRODUÇÃO}

No Brasil, a implantação de reservatórios artificiais para o armazenamento de água decorreu da grande necessidade de provisão deste bem para a população. Como primeiro registro de construção de barragem no território brasileiro, tem-se a barragem de Apipucos, no estado do Pernambuco, com datação atribuída ao final do século VXI (CBDB, 2011). Tal reservatório foi implantado em uma região onde historicamente, a açudagem é a principal política de obras para a relação com as secas (CIRILO, 2008). No semiárido nordestino, a construção de reservatórios decorreu da necessidade de o homem sertanejo resistir às condições naturais desta região. De

${ }^{1}$ Alisson Medeiros de Oliveira, UFRN/DGC, Grupo de Pesquisa sobre Estudos Geoambientais do Semiárido - GESA, Caicó-RN, Brasil

${ }^{2}$ Diógenes Félix da Silva Costa, UFRN/DGC, Grupo de Pesquisa sobre Estudos Geoambientais do Semiárido - GESA, Caicó-RN, Brasil

${ }^{3}$ Elza Edimara Soares da Silva, UFRN/DGE, Grupo de Pesquisa sobre Dinâmicas Ambientais, Risco e Ordenamento do Território GEORISCO, Natal-RN, Brasil

${ }^{4}$ Wanderson Silva de Araújo, UFRN/DGC, Grupo de Pesquisa sobre Estudos Geoambientais do Semiárido - GESA, Caicó-RN, Brasil 
acordo com Rebolsas (1997), as "secas" de 1825, 1827 e 1830 balizaram a construção de barramentos na região semiárida.

Com médias pluviométricas abaixo de $800 \mathrm{~mm} \cdot \mathrm{ano}^{-1}$, temperaturas médias entre $26^{\circ} \mathrm{C}$ e $28^{\circ} \mathrm{C}$, umidade do ar em torno de $65 \%$ e insolação anual de mais de 3.000 h.ano ${ }^{-1}$ em alguns pontos, ocorre uma evaporação potencial de 2.000 a $2.500 \mathrm{~mm}_{\text {ano }}{ }^{-1}$, o que excede a capacidade de recarga. Somando-se a isso, temos a drenagem superficial efêmera, gerando um balanço hídrico negativo, o que reduz a disponibilidade hídrica (REBOLSAS, 1997; AB'SABER, 2003; CIRILO, 2008; INSA, 2011). Diante das condições de semiaridez, os reservatórios assumem extrema relevância no quadro de recursos hídricos do Nordeste.

Segundo Junk et al. (2014) e Ramsar (2013) os lagos derivados de barragens são classificados como áreas úmidas (wetlands), de elevada importância em decorrência dos diversos serviços prestados as sociedades. Dessa forma, estes reservatórios, por proverem inúmeros serviços ecossistêmicos, tornam-se peças chave em qualquer quadro regional. (TUNDISI; MATSUMURATUNDISI; TUNDISI, 2008).

Costanza et al. (1997) afirmam que os ecossistemas podem prover serviços, como: a purificação do ar e da água, provisão de recursos naturais, regulação da biodiversidade, reciclagem e serviços recreacionais. No âmbito desta temática, é crescente o número de estudos acerca dos serviços ecossistêmicos, tanto para a descrição quanto para a valoração (e. g. COSTANZA et al., 1997; JORGENSEN, 2010; BURKHARD et al., 2010; DE GROOT et al., 2010).

Muito embora haja uma ampla discussão vigente sobre funções ecossistêmicas, é necessário que se façam tais estudos, tendo em vista que essas abordagens permitem um amplo catálogo de informações sobre os serviços; produzem aproximações teóricas e práticas, além de resultados primários; criam perspectivas futuras para os ecossitemas e estimulam vários tipos de pesquisas, devido sua relevância científica (COSTANZA et al., 1997). O prévio conhecimento dos benefícios ecossistêmicos permitem que ações sejam praticadas para otimizar os serviços, ou que nenhuma interferência que minore um ou mais serviços seja feita (BURKHARD et al., 2010). No Brasil, pesquisas acerca dos serviços ecossistêmicos prestado por reservatórios têm sido desenvolvidas por Tundisi; Matsumura-Tundisi; Tundisi (2008); Tundisi; Matsumura-Tundisi; Periotto (2012) e Periotto; Tundisi (2013).

No Nordeste do Brasil, os reservatórios são amplamente estudados (e. g. GURGEL, 1990; GURGEL; COSTA, 1994; MOLLE, 1994; BOUVY; BARROS-FRANÇA; CAMOUZE, 1998; ARAÚJO, 2003; BARBOSA et al., 2012; FARIA, 2012; SANTOS-JÚNIOR, 2013; COSTA; GUEDES; ROCHA, 2014). Contudo, pouco se conhece acerca dos serviços ecossistêmicos prestados por reservatórios do semiárido, e tal conhecimento seria vital para a valorização dos 
recursos hídricos dessa região, principalmente para o ordenamento do território tanto a nível de bacia hidráulica quanto a bacia hidrográfica.

Neste contexto, o presente estudo buscou analisar os principais serviços ecossistêmicos prestados pelos reservatórios do semiárido do Brasil, com vistas não apenas na valorização da água como bem de consumo direto, mas também evisdenciado-se outros importantes serviços prestados por estes ecossistemas, os quais podem subsidiar políticas públicas de gerenciamento integrado a nível local e regional.

\section{METODOLOGIA}

O estudo foi realizado através de levantamentos de dados de campo e cruzamento de informações científicas já publicadas sobre os reservatórios da Região Nordeste do Brasil. Em escala macrorreional, foram visitados os seguintes reservatórios: Orós-CE (6'14'18"S e 3855'30" O), Castanhão-CE (5²9'46" S e 38²6'40" O), Eng. Armando Ribeiro Golçaves-RN (540'09" S e 3652'52" O), Coremas-Mãe-d'Água-PB (701'30" O e 3756'52" S), Sobradinho-BA (9²6'30" S e 4049'19" O), Paulo Afonso-PE/BA (9²4'56" S e 38 12'01" O) e Xingó - AL/BA/SE (09³7'12" S e 3747'28" O). Para fins de maior detalhamento dos serviços ecossistêmicos em escala microrregional, foram visitados os reservatórios incluídos no Polo de Desertificação do Seridó (RN/PB), na seguinte lista: Ministro João Alves - Parelhas/RN (641'40" S e 38 37'43" O), CruzetaCruzeta/RN (6²4'37" S e 3647'47" O), Marechal Dutra-Acari/RN (6²5'41" S e 36 36'10" O),

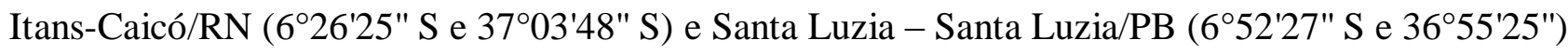
(figura 01). 


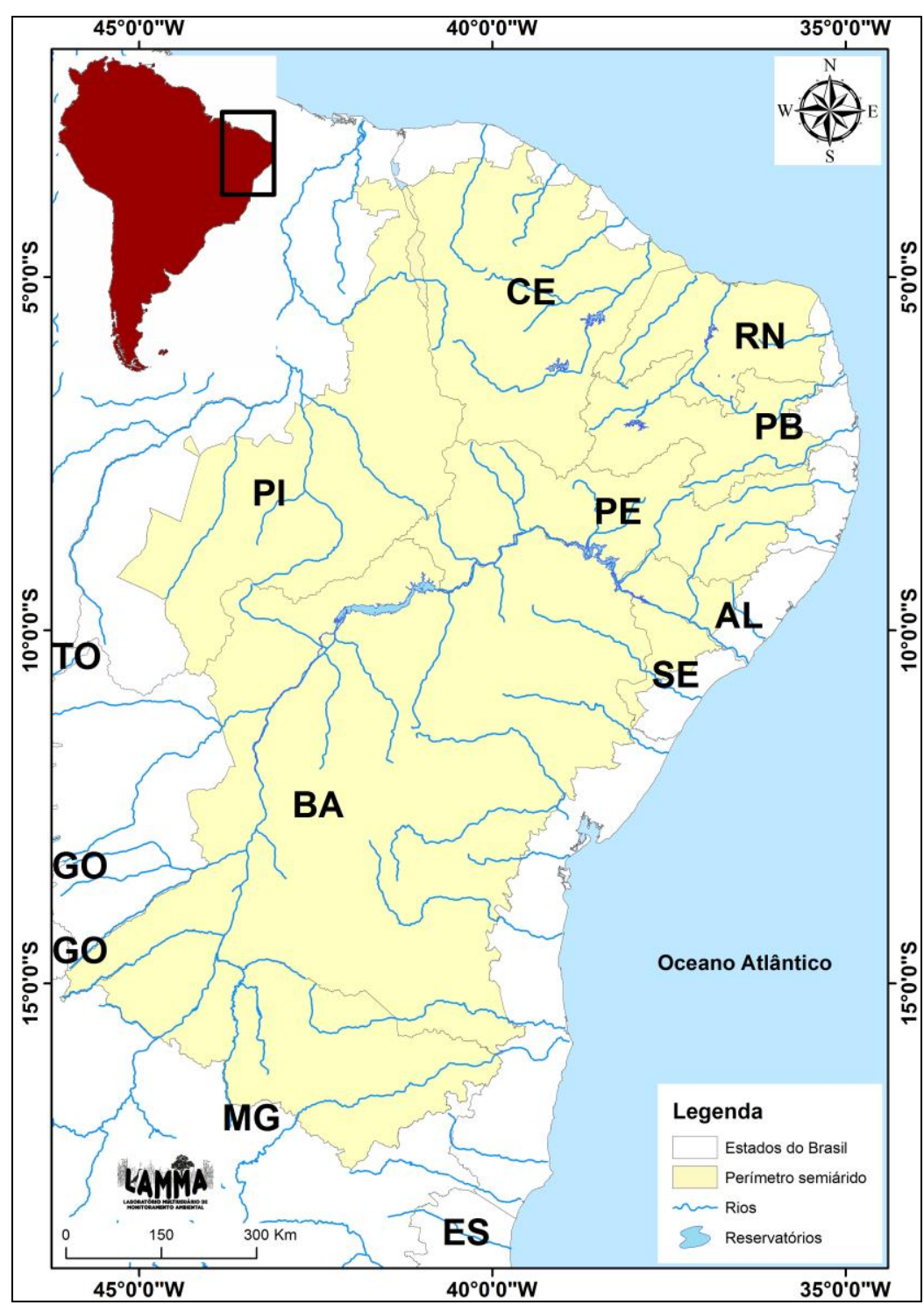

Figura 01: Reservatórios do perímetro semiárido do Brasil Fonte: Elaborado pelos autores.

A base teórica dos serviços foi obtida a partir dos estudos de Tundisi; Matsumura-Tundisi; Tundisi, (2008); De Groot et al., (2010); Burkhard et al., (2010); Tundisi; Matsumura-Tundisi; Periotto (2012); Periotto; Tundisi (2013); Ramsar (2013) e de Costa et al. (2014).

Com o objetivo evidenciar a importância dos reservatórios, suas funções e serviços prestados, realizou-se uma análise dentro do quadro DPSIR (Drivers, Pressures, State, Impact, Responses) (EEA, 1999). A categoria "Drivers" refere-se às necessidades humanas que geram os usos do meio ambiente (podendo ser chamada de "força motriz"), "Pressures" diz respeito às pressões geradas pela necessidade de uso; "State" implica na qualidade do ambiente em virtude das pressões, que por sua vez gerará um impacto ("Impact") sobre os ecossistemas, alterando a qualidade dos serviços, o que demandará das sociedades respostas ("Responses"), que pode ser em 
forma de políticas públicas com o objetivo de recuperar o meio ambiente e as funções desempenhadas (EEA, 1999; KRISTENSEN, 2004).

\section{RESULTADOS E DISCUSSÃO}

Quando os reservatórios estão com bom volume de água ou com água disponível, são prestados os seguintes serviços (Figura 02):

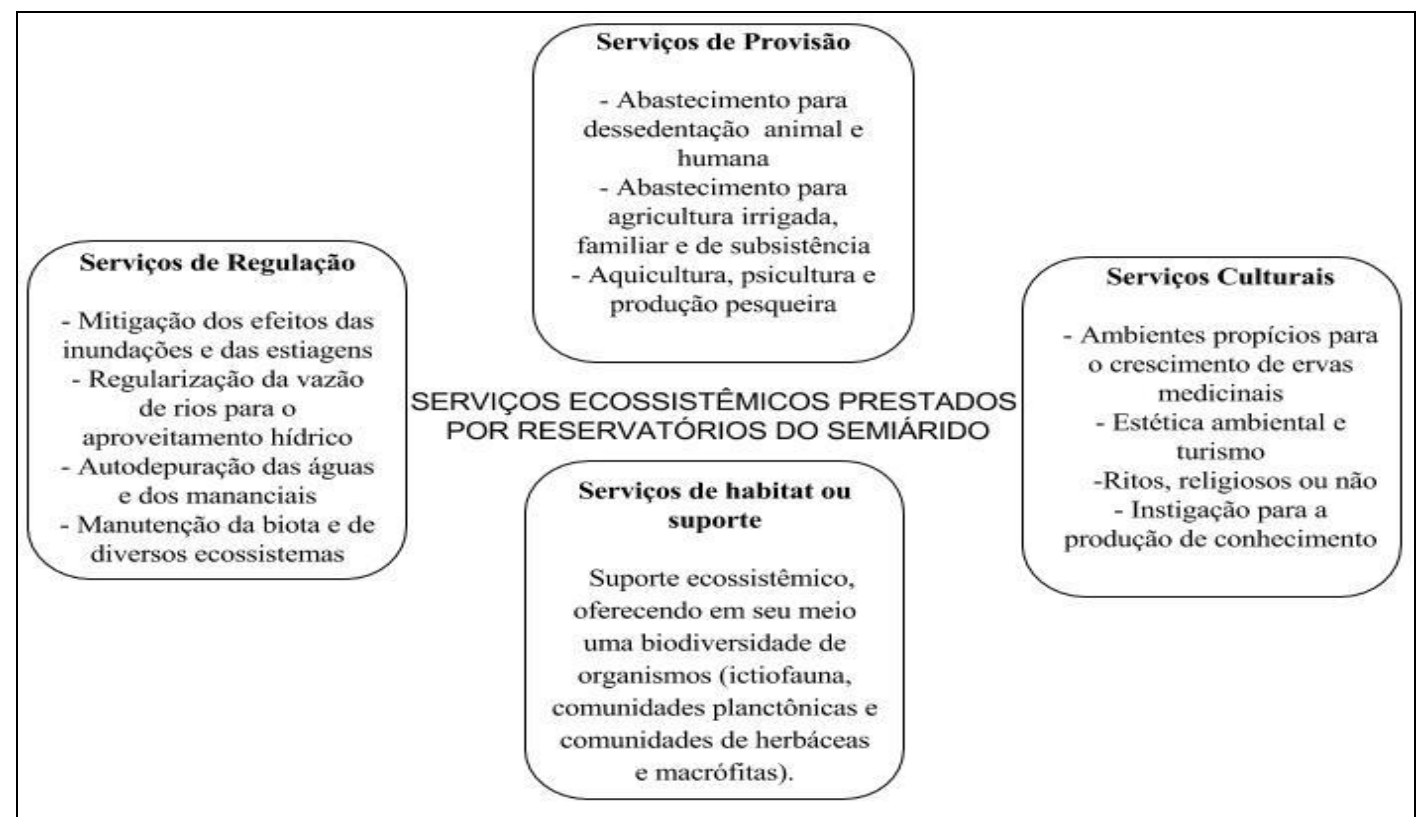

Figura 02: Principais benefícios ambientais dos reservatórios do perímetro semiárido do Brasil

Fonte: Elaborado pelos autores com base em TEEB (2010).

Pelo fato de os lagos artificiais do semiárido sofrerem com pressões climáticas da semiaridez, fazendo com que estes percam parcialmente ou totalmente o seu volume de água, a durabilidade dos serviços ecossistêmcos é limitada. Com a perca de água e de área de espelho d'água, alguns serviços são suprimidos ou minimizados (Figura 03). Portanto, no período seco ou com a degradação das águas os serviços prestados por reservatórios podem ter variações anuais e plurianuais. A seguir, é mostrado os serviços prestados em períodos de estiagem (reservatórios com baixo volume de água). 


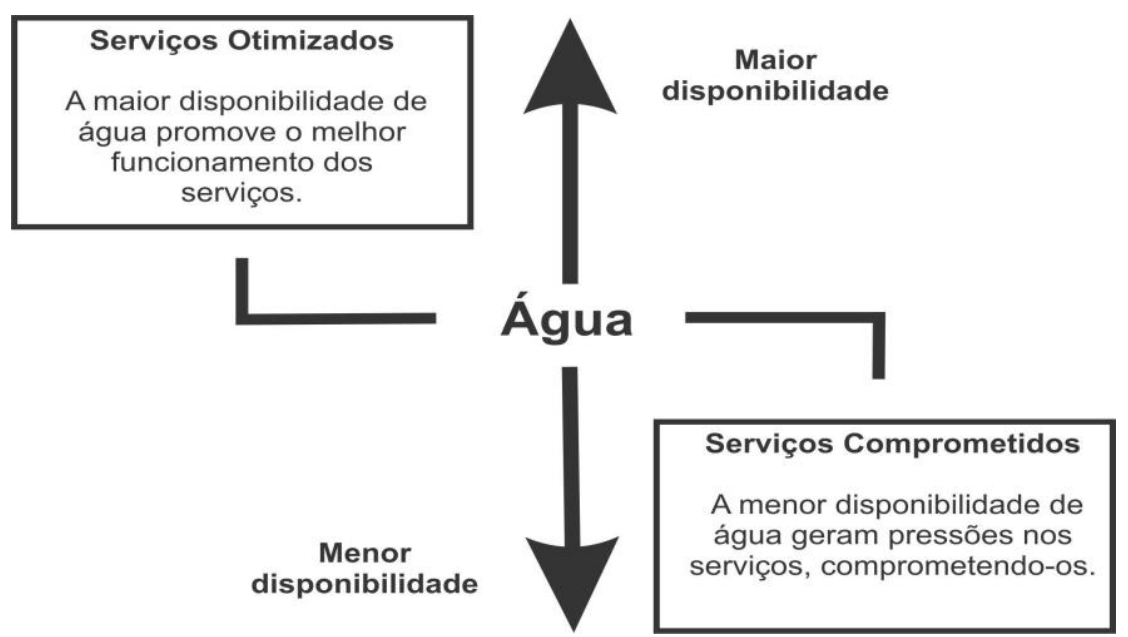

Figura 03: Os Níveis dos reservatórios influenciam no bom funcionamento dos serviços, assim como na intensidade dos usos dos benefícios, podendo minimizá-los.

Fonte: Acervo dos autores.

1) Serviços de provisão: Com a escassez de água, os serviços de provisão de água, de alimentos, água para descedentação animal e abasteciemento humano são afetados. No caso de reservatórios que secam totalmante, boa parte dos serviços de provisão são suprimidos, a exceção são aqueles que ainda se sustentam com a água presente no lençol freático.

2) Serviços de regulação: O serviço de minoração dos efeitos das secas é o mais duradouro, contudo, quando o reservatório não tem mais água, este é reduzido a apenas a extração de água do lençol freático. Com a gradativa perca de água, os serviços de regulação do meio físico vão se reduzindo, principalmente o de autodepuração da água.

3) Serviços de habitat ou suporte: Com baixo volume de água, a disponibilidade de água na bacia de capitação dos reservatórios diminuie, afetando não só as comunidades humanas, mas também para as comunidades vegetais e animais. A água é o principal fator dos serviços pretados pelos aos ecossistemas, com sua escasses, este servição são minimizados. Sendo assim, os habtats proporcionados pelos reservatórios são, muitas vezes, temporários.

4) Serviços culturais: Estes são os serviços ambientais mais prejudicados, isto porque eles dependem exclusivamente da disponibilidade da água, e de boa qualidade (sem, no mínimo, poluição). Num período seco, com baixos volumes de água, as atividades turísticas e religiosas cessam. Os serviços estéticos da pasiagem sofrem alterações, principalmente aqueles relacionados a água.

\section{Análise DPSIR}

O quadro de análise DPSIR apresenta competência para gerir os serviços prestados por reservatórios no semiárido, uma vez que este proporciona uma visão integrada dos usos, serviços e pressões geradas. As necessidades humanas quanto aos usos dos reservatórios são intrinsecamente 
ligadas aos serviços de provisão, ou seja, a providência de água para satisfazer e dar suporte a atividades das comunidades humanas.

Tabela 1: Análise DPISIR e principais serviços ambientais dos reservatórios. Fonte: Acervo dos autores.

\section{SERVIÇOS ECOSSISTÊMICOS PRESTADOS POR RESERVATÓRIOS (S)}

S1 - Abastecimento para dessedentação humana e animal

S2 - Abastecimento para a agricultura irrigada, familiar e de subsistência

S3 - A aquicultura, psicultura e produção pesqueira

S4 - Mitigações dos efeitos das inundações e das estiagens

S5 - Regularização da vazão de rios para o aproveitamento hídrico

S6 - A autodepuração das águas e dos mananciais

S7 - Manutenção da biota de diversos ecossistemas

S8 - Regulação de fatores abióticos (água, oxigênio, Ph das águas e dos solos, hidrogeoquímica, etc.)

S9 - Suporte ecossistêmicos, oferecendo em seu meio uma biodiversidade de organismos (ictiofauna, comunidades planctônicas e comunidades de herbáceas e macrófitas)

S10 - Ambientes propícios para o crescimento de ervas medicinais

S11 - Estética ambiental e turismo

S12 - Ritos, religiosos ou não.

S13 - Instigação para a produção de conhecimento

\section{DRIVERS (D)}

D1 - Abastecimento para dessedentação humana e animal

D2 - Agricultura irrigada, familiar e de subsistência

D3 - Aquicultura, psicultura e produção pesqueira

D4 - regularizar e minorar os efeitos das secas e das cheias

\section{PRESSÕES (P)}

P1 - Uso intensivo das águas e condições climáticas do semiárido

P2 - destino final das águas servidas e posterior eutrofização

P3 - Assoreamento

ESTADO (E)

E1 - Exaustão dos reservatórios, a queda da disponibilidade hídrica

E2 - Contaminação e eutrofização de suas águas

E3 - Reservatório assoreado

\section{IMPACTO (I)}

I1 - S1, S4 e S5 comprometidos e potencialmente suspensos

I2 - S2 e S3 comprometidos e potencialmente suspensos

I3 - S6 comprometido

I4 - comprometimento dos S11, S12 e S13

I5 - S7, S8, S9 e S10 comprometidos e potencialmente suspensos

\section{RESPOSTAS (R)}

R1 - Manejo de bacias, sub-bacias e micro-bacias hidrográficas do semiárido

R2 - Destino correto de águas servidas e resíduos sólidos

R3 - Adoção e implantação de outras políticas públicas de convivência com semiárido

Dessa forma, tem-se como primeiro "Drivers" (D1) o abastecimento para dessedentação humana e animal, sendo este o fator crucial para a cosntrução de reservatórios no Nordeste. No 
meio rural, os reservatórios se destacam por fomentar a agricultura familar, de subsistência e áreas irrigadas (D2). A aquicultura, psicultura e produção pesqueira (D3) são alterativas econômicas para a população ribeirinha, sendo a última muito presente nos reservatórios do semiárido. Por fim, a irregularidade pluviométrica e a concentração do período chuvoso em 4 ou 5 meses geram, por vezes, eventos de cheias que prejudicam e danificam cidades ribeirinhas. Com o intuíto de regularizar as cheias (D4), muitos reservatórios forma construídos.

A ampla ultilização dos recursos hídricos para o abastecimento e dessedentação humana e animal, juntamente com as condições climáticas de semiaridez (P1) causam a exaustão dos reservatórios, a queda da disponibilidade hídrica (E1). Em virtude das barragens serem cosntruídas nos leitos dos rios, os quais são o destino final das águas servidas (P2), estes sofrem com a contaminação e eutrofização de suas águas, tornando-a imprópria para consumo humano (E2). A utilização dos recursos vegetais (lenha) da Caatinga acaba por deixar diversas áreas de uma bacia hidrográfica com solos expostos, os quais passam a sofrer ações intempéricas, tendo seus sedimentos carreados para os leitos e rios, e mais adiante, para as bacias hidráulicas dos reservatórios, assoreando-os (P3). Um reservatório assoreado (E3) intensifica as pressões de P1.

Os estados nos quais se encontram os reservatórios alteram e/ou interferem nos serviços prestados (EEA, 1999; KRISTENSEN, 2004). Sendo assim, o maior impacto que um novo estado pode causar é de indisponibilidade hídrica para dessedentação humana e animal (I1), seguida da possibilidade de que uma água imprópria pode cessar a atividade pesqueira, além de prejudicar a agricultura (I2) e o serviço de autodepuração da água (I3). Um reservatório assoreado e com águas poluídas ou contaminadas podem afastar banhistas e turistas (I4), assim como causar o comprometimento dos serviços de manutenção de habitas e de manutenção de comunidades aquáticas e terrestres (I5).

Diante dos impactos sofridos, as sociedades e comunidades humanas têm alternativas para minimizar os impactos e maximizar os benefícios ambientais. A primeira resposta (R1) seria o manejo de bacias, sub-bacias e micro-bacias hidrográficas do semiárido, uma vez que o manejo destas minimizaria boa parte dos impactos (I1, I2, I3 e I4). Estas respostas têm base legal na lei $\mathrm{n}^{\circ}$ 9.433, que institui a Política Nacional de Recursos Hídricos (BRASIL, 1997). Uma resposta para mitigar impactos I4, I5 e I6 (R2) seria o destino correto de águas servidas e resíduos sólidos, as quais são amparadas pelas leis $\mathrm{n}^{\circ} 11.445$ (Política Federal de Saneamento Básico) (BRASIL b, 2007) e $n^{\circ} 12.305$ (Política Nacional de Resíduos Sólidos) (BRASILc, 2010).

Os reservatórios são frutos de políticas públicas de recursos hídricos, e são justamente os mais difundidos e utilizados, gerando uma forte dependência dos mesmos. Para que se possa 
diminuir a dependência dos reservatórios ou para fins alternativos de provisão de água, a terceira resposta (R3) seria a adoção outras políticas públicas de convivência com semiárido.

Segundo De Groot et al. (2010), a avaliação de serviços ecossistêmicos podem mudar a discussão sobre a conservação do meio ambiente. É importante frisar que um levantamento acerca dos serviços ecossistêmicos envolvendo os recursos hídricos do semiárido é de extrema importância para a valorização e conservação dos mesmos.

Os serviços ecossistêmicos prestados por açudes no semiárido do Brasil são, no geral, semelhantes aos observados e catalogados por Periotto; Tundisi (2013) para a UHE Lobo-Broa/SP, dos quais se destacam os serviços de provisão (S1, S2 e S3). Em outro trabalho, relacionado aos reservatórios neotrópicos, Tundisi; Matsumura-Tundisi; Tundisi (2008) identificaram que estes apresentam serviços variados, que contribuem para o bem estar humano (saúde, necessidades básicas, renda, segurança e fortalecimento de relações), porém, mais uma vez os serviços de maior relevância foram os serviços de providência (água, alimentos referentes a pescados e atividades de irrigação). Assemelha-se ainda aos benefícios ambientais dos açudes do semiárido, aos estudos de Tundisi; Matsumura-Tundisi; Tundisi, (2008); Tundisi; Matsumura-Tundisi; Periotto (2012); que destacaram serviços como regulações de cheias, manutenção da qualidade das água e biodiversidade.

Em pesquisas sobre a principal finalidade das barragens dos Estados Unidos, Cech (2013) verificou a recreação como a principal utlidade das barragens e seus reservatórios, sendo que a finalidade "abastecimento de águas" legava a quinta maior finalidade. É muito provável que a grande importância dos serviços de provisão e de manutenção prestados pelas barragens do Nordeste seja em virtude de suas finalidades, que é a de dar providência de água para dessedentação humana e animal, além do suporte para áreas irrigadas e contenção de cheias (SUDENE, 1966; SUDENE, 1966b).

Contudo, em nenhum dos estudos foi levantado a questão da duração dos serviços, ou seja, o tempo e os fatores pelos quais apresentam interlavo de ocorrência. Em relação aos reservatórios do semiárido, a pressão do clima semiárido é o principal fator que rege o tempo do serviço prestado. A pressão climática é o controle de estrada de água na bacia hidráulica dos reservatórios, quanto menor o volume, menor será o potencial dos serviços oferecidos.

Todavia, são nos perídos de estiagens que se destacam boa parte dos serviços que intereçam a permanência e ao bem-estar humano no semiárido. Por este motivo, é chamado a atenção pelo manejo dos recursos hídricos do Nordeste do Brasil, principalmente para os perídos de secas meteorológicas. 
Neste contexto, com vistas para o melhor tratamento dos recursos hídricos do semiárido (figurado principalmente pelos reservatórios), este estudo fundamentou alternativas de manejo (R1, R2 e R3) diante dos resultados apresentados pelo quadro DPSIR. A análise DPSIR se mostra eficaz em diversos estudos (e. g. para bacias hidrográficas (SOARES et al., 2011) e para ecossistemas salinos (COSTA et al., 2014).

\section{CONSIDERAÇÕES FINAIS}

O prévio conheciento dos benefícios ecossistêmicos dos reservatórios do semiárido é uma estratégia de manejos dos mesmos, uma vez que este saber permite aos gestores a tomada de decisões que possam maximizar estes benefícios. Verificou-se que o serviço mais relevante e mais prestado a sociedade é o serviço de provisão, portanto, ações devem ser tomadas visando maximizar o potencial e as áreas potenciais prestadoras deste serviço, assim como é imprenscindível a valorização e conservação da água no semiárido.

\section{REFERÊNCIAS}

AB' SABER, A. Z. Os domínios da natureza no Brasil: potencialidades paisagísticas. 4 ed. São Paulo: Ateliê Editorial, 2003. 159 p.

ARAÚJO, J. C. Assoreamento em reservatórios do semi-árido: modelagem e validação. RBRH Revista Brasileira de Recursos Hídricos. v. 8 n. 2, p. 39-56, 2003.

BARBOSA, J. E. L.; MEDEIROS, E. S. F.; BRASIL, J.; CORDEIRO, R. S.; CRISPIM, M. C. B.; SILVA, G. H. G. Aquatic systems in semi-arid Brazil: limnology and management. Acta Limnologica Brasiliensia, v. 24, n. 1, p. 103-118, 2012.

BOUVY, M.; BARROS-FRANÇA, L. M.; CAMOUZE, J. P. Comportamento microbiano no meio pelágico de sete açudes no estado de Pernambuco. Acta Limnologica Brasiliensia, v. 10, n. 1, 93101, 1998.

BRASIL. Política Nacional de Recursos Hídricos. Disponível em: <http://www.planalto.gov.br/ccivil_03/LEIS/L9433.htm>. Acesso em: 22/10/2015.

BRASIL b. Política Nacional de Saneamento Básico. Disponível em: <http://www.planalto.gov.br/ccivil_03/_ato2007-2010/2007/lei/111445.htm >. Acesso em: 22/10/2015.

BRASIL c. Política Nacional de Resíduos Sólidos. Disponível em: <http://www.planalto.gov.br/ccivil_03/_ato2007-2010/2010/lei/112305.htm >. Acesso em: 22/10/2015.

BURKHARD, B.; PETROSILLO, I.; COSTANZA, R. Ecosystem services - Bridging ecology, economy and social sciences. Ecological Complexity, v. 7, p. 257-259, 2010.

CBDB. Comitê Brasileiro de Barragens. A história das barragens no Brasil, Séculos XIX, XX e XXI : cinquenta anos do Comitê Brasileiro de Barragens. Rio de Janeiro: CBDB, 2011. 524 p.

CECH, T. V. Recursos hídricos: História, desenvolvimento, política e gestão. Rio de Janeiro: LTC, 2013. 428 p.

CIRILO, J. A. Políticas públicas de recursos hídricos para o semi-árido. Estudos Avançados, São Paulo, v.22, n.63, p. 61-82, 2008.

COSTANZA, R.; D’ARGE, R.; DE GROOT, R.; FARBER, S.; GRASSO, M.; HANNON, B.; LIMBURG, K.; NAEEM, S.; O’NEILL, R. V.; PARUELO, J.; RASKIN, R. G.; SUTTON, P.; 
VAN DEN BELT, M. The value of the world's ecosystem services and natural capital. Nature, v. 387, p. 253-260, 1997.

COSTA, D. F. S.; GUEDES, J. C. F.; ROCHA, R. M.; Estratégia de zoneamento ambiental aplicada a gestão das margens de reservatórios. Revista de Geografia (UFPE) v. 31, n. 2, p. 109$122,2014$.

COSTA, D. F. S; ROCHA, R. M; BARBOSA, J. E. L; SOARES, A. M.V. M; LILLEBO, A. I. Análise dos serviços ambientais prestados pelas salinas solares. Boletim Gaúcho de Geografia, v. 41, p. 206-220, 2014.

DE GROOT, R.S.; ALKEMADE, R.; BRAAT, L.; HEIN, L.; WILLEMEN, L. Challenges in integrating the concept of ecosystem services and values in landscape planning management and decision making. Ecological Complexity, v. 7, p. 260-272, 2010.

EEA. European Environmental Agency. Environmental indicators: Typology and overview. Disponível em: < http://www.eea.europa.eu/publications/TEC25>. Acesso em: 30/09/15.

GURGEL, J. J. S. Pesca em açudes construídos no Brasil, principalmente na região do semiárido. Caatinga, v. 7, 190-206, 1990.

GURGEL, J. J. S.; COSTA, R. S. Sobre a produtividade da pesca em 16 açudes públicos da bacia hidrográfica do rio Jaguaribe, Ceará, Brasil. Caatinga, v. 8, n. 2, p. 58-67, 1994.

ICOLD. INTERNATIONAL COMMISSION ON LARGE DAMS. As barragens e a água do mundo.

Disponível:

<http://www.cbdb.org.br/publicacoes/dams_and_the_worlds_water_traducao.pdf $>$. Acesso em: $14 / 08 / 2015$.

INSA. Desertificação e Mudanças Climáticas no Semiárido Brasileiro. Campina Grande: INSAPB, 2011. 209 p.

JORGENSEN, S. E. Ecosystem services, sustainability and thermodynamic indicators. Ecological Complexity, v. 7, p. 311-313, 2010.

JUNK, W. J.; PIEDADE, M. T. F.; LOURIVAL, R.; WITTMANN, F.; KANDUS, P.; LACERDA, L. D.; BOZELLI, R. L.; ESTEVES, F. A.; NUNES DA CUNHA, C.; MALTCHIK, L.; SCHÖNGART, J. SCHAEFFER-NOVELLI, Y.; AGOSTINHO, A. A.; Brazilian wetlands: their definition, delineation, and classification for research, sustainable management, and protection, Aquatic Conserv: Mar. Freshw. Ecosyst., v. 24, p. 5-22, 2014.

KRISTENSEN, P. The DPSIR framework. Denmark: National Environmental Research Institute. Disponível em: <http://wwz.ifremer.fr/dce/content/download/69291/913220/file/DPSIR.pdf . Acesso em: 30/09/15.

MOLLE, F. Marcos históricos e reflexões sobre a açudagem e seu aproveitamento. Recife: SUDENE, 1994. 193 p.

MONTENEGRO, A. A. A; MONTENEGRO, S. M. G. L. Olhares sobre as políticas públicas de recursos hídricos para o semiárido. IN: GHEYI, H. R; PAZ, V. P. S; MEDEIROS, S. S; GALVÃO, C. O. (Orgs.). Recursos hídricos em regiões semiáridas. Campina Grande: INSA, 2012, pp. 1-28. REBOLSAS, A. C. Água na região Nordeste: desperdício e escassez. Estudos Avançados. São Paulo: v.11, n.29, p. 127-154, 1997.

RAMSAR. The Ramsar Convention Manual: a guide to the Convention on Wetlands (Ramsar, Iran, 1971) 6 ed. Gland, Switzerland: Ramsar Convention Secretariat, 2013. 109 p.

SANTOS JÚNIOR, R.R. dos. A influência do lago artificial do Castanhão no sistema climático local do Vale do Rio Jaguaribe - CE. Revista GeoUECE, v. 2, n. 1, p. 176-177, 2013.

SOARES, A. B; SILVA-FILHO, J. C. L; ABREU, M. C. S; SOARES, F. A. Revisando a estruturação do modelo DPSIR como base para um sistema de apoio à decisão para a sustentabilidade de bacias hidrográficas. Revista em Agronegócios e Meio Ambiente, v. 4, n. 3, p. 521-545, 2011.

SUDENE. I Plano Diretor de Desenvolvimento Econômico e Social do Nordeste 1961-1963. Recife: Div. Documentação, 1966. 254 p. 
b. II Plano Diretor de Desenvolvimento Econômico e Social do Nordeste 19631965.Recife: Div. Documentação, 1966. 100 p.

TEEB - The Economics of Ecosystems and Biodiversity. A Quick Guide: The Economics of Ecosystems and Biodiversity for Local and Regional Policy. TEEB. 2010a

THORTON, K. W; KIMMEL, B. L; PAYNE, F. E. (Orgs). Reservoir Limnology: ecological perspectives. New York: A Wiley-Interscience, 1990. p. 1-13

TUNDISI, J. G; MATSUMURA-TUNDISI, T. Limnologia. São Paulo: Oficina de Textos, 2008. $631 \mathrm{p}$.

TUNDISI, J. G.; MATSUMURA-TUNDISI, T.; TUNDISI, J. E. M. Reservoirs and human well being: new challenges for evaluating impacts and benefits in the neotropics. Brazilian Journal of Biology, v. 69, n. 4, p. 1133-1135, 2008.

TUNDISI, J. G.; MATSUMURA-TUNDISI, T.; PERIOTTO, N. A. Exergy and ecological services in reservoirs. Braz. J. Biol., v.72, n. 4, p. 979, 2012.

PERIOTTO, N. A.; TUNDISI, J. G. Ecosystem Services of UHE Carlos Botelho (Lobo/Broa): a new approach for management and planning of dams multiple-uses. Braz. J. Biol., v. 73, n. 3, p. 471-482, 2013.

Recebido em: 14/08/2016

Aceito para publicação em: 01/10/2016 